Adenovirus Methods and Protocols 


\title{
METHODS IN MOLECULAR MEDICINE
}

\author{
John M. Walker, SERIES EDITOR
}

29. DNA Vaccines: Methods and Protocols, edited by Douglas B. Lowrie and Robert Whalen, 1999

28. Cytotoxic Drug Resistance Mechanisms, edited by Robert Brown and Uta Böger-Brown, 1999

27. Clinical Applications of Capillary Electrophoresis, edited by Stephen M. Palfrey, 1999

26. Quantitative PCR Protocols, edited by Bernd Kochanowski and and Udo Reischl, 1999

25. Drug Targeting, edited by G. E. Francis and Cristina Delgado, 1999

24. Antiviral Chemotherapy Protocols, edited by Derek Kinchington and Raymond F. Schinazi, 1999

23. Peptidomimetics Protocols, edited by Wieslaw M. Kazmierski, 1999

22. Neurodegeneration Methods and Protocols, edited by Jean Harry and Hugh A. Tilson, 1999

21. Adenovirus Methods and Protocols, edited by William S. M. Wold, 1999

20. Sexually Transmitted Disease Protocols, edited by Rosanna Peeling and P. Frederick Sparling, 1999

19. Hepatitis C Protocols, edited by Johnson Y. N. Lau, 1998

18. Tissue Engineering Methods and Protocols, edited by Jeffrey R. Morgan and Martin Yarmush, 1999

17. HIV Protocols, edited by Nelson Michael and Jerome H. Kim. 1999

16. Clinical Applications of PCR, edited by Y. M. Dennis Lo, 1998

15. Molecular Bacteriology: Protocols and Clinical Applications, edited by Neil Woodford and Alan P. Johnson, 1998

14. Tumor Marker Protocols, edited by Margaret Hanausek and Zbigniew Walaszek, 1998

13. Molecular Diagnosis of Infectious Diseases, edited by Udo Reischl. 1998

12. Diagnostic Virology Protocols, edited by John R. Stephenson and Alan Warnes, 1998

11. Therapeutic Applications of Ribozymes, edited by Kevin J. Scanlon, 1998

10. Herpes Simplex Virus Protocols, edited by S. Moira Brown and Alasdair R. MacLean, 1998

9. Lectin Methods and Protocols, edited by Jonathan M. Rhodes and Jeremy D. Milton, 1998

8. Helicobacter pylori Protocols, edited by Christopher L. Clayton and Harry L. T. Mobley, 1997

7. Gene Therapy Protocols, edited by Paul D. Robbins, 1997

6. Molecular Diagnosis of Cancer, edited by Finharr E. Cotter. 1996

5. Molecular Diagnosis of Genetic Diseases, edited by Rob Elles, 1996

4. Vaccine Protocols, edited by Andrew Rohinson, Graham H. Farrar, and Christopher N. Wiblin, 1996

3. Prion Diseases, edited by Harry F. Baker and Rosalind M. Ridley, 1996

2. Human Cell Culture Protocols, edited by Gareth E. Jones, 1996

1. Antisense Therapeutics, edited by Sudhir Agrawal, 1996 


\section{METHODS IN MOLECULAR MEDICINE}

\section{Adenovirus Methods and Protocols}

Edited by

\section{William S. M. Wold}

St. Louis University Health Science Center, St. Louis, MO

Humana Press 深 Totowa, New Jersey 
(c) 1999 Humana Press Inc.

999 Riverview Drive, Suite 208

Totowa, New Jersey 07512

All rights reserved. No part of this book may be reproduced, stored in a retrieval system, or transmitted in any form or by any means, electronic, mechanical, photocopying, microfilming, recording, or otherwise without written permission from the Publisher. Methods in Molecular Medicine' is a trademark of The Humana Press Inc.

All authored papers, comments, opinions, conclusions, or recommendations are those of the author(s), and do not necessarily reflect the views of the publisher.

This publication is printed on acid-free paper. $\infty$

ANSI Z39.48-1984 (American Standards Institute) Permanence of Paper for Printed Library Materials.

Cover design by Patricia F. Cleary.

For additional copies, pricing for bulk purchases, and/or information about other Humana titles, contact Humana at the above address or at any of the following numbers: Tel.: 973-256-1699; Fax: 973-256-8341; E-mail: humana@humanapr.com; Website: http://humanapress.com

\section{Photocopy Authorization Policy:}

Authorization to photocopy items for internal or personal use, or the internal or personal use of specific clients, is granted by Humana Press Inc., provided that the base fee of US $\$ 8.00$ per copy, plus US $\$ 00.25$ per page, is paid directly to the Copyright Clearance Center at 222 Rosewood Drive, Danvers, MA 01923. For those organizations that have been granted a photocopy license from the $\mathrm{CCC}$, a separate system of payment has been arranged and is acceptable to Humana Press Inc. The fee code for users of the Transactional Reporting Service is: $[0-89603-551-4 / 99 \$ 8.00+\$ 00.25]$.

Printed in the United States of America. 109687765543221

Library of Congress Cataloging in Publication Data

Main entry under title:

Methods in molecular medicine ${ }^{\mathrm{Tu}}$.

Adenovirus methods and protocols / edited by William S. M. Wold.

p. cm. -- (Methods in molecular medicine ${ }^{\mathrm{ru}}$; vol. 21)

Includes index.

ISBN 0-89603-551-4 (alk. paper)

1. Adenoviruses - Laboratory manuals. 2. Molecular biology - Laboratory manuals.

I. Wold, William S. M. II. Series: Methods in molecular medicine; 21.

QR396.A336 1998

$579.2 ' 443-\mathrm{dc} 21$ 


\section{Preface}

Since their discovery in 1954, adenoviruses (Ads) have become a premier and prolific model for studying cell biology. Ads are benign to the researcher, easy to grow and manipulate, stable, versatile, and extremely interesting. Not only do they replicate reproducibly, but they also can transform cells to an oncogenic state. About half of the $\sim 40$ Ad proteins physically interact with key cellular proteins and subvert them for use by the virus. Many of these proteins or mechanisms have been discovered and/or elucidated through Ad research. Examples include splicing, transcription regulation through transcription factors such as E2F, p53, and transcriptional adaptor proteins (p300/ $\mathrm{CBP}, \mathrm{pRB}$, and family members), and regulation of apoptosis. Ads and retroviruses have launched experimental gene therapy.

Adenovirus Methods and Protocols is designed to help new researchers to conduct studies involving Ads, and to help established researchers to branch into new areas. The chapters, which are written by prominent investigators, provide a brief general background to a topic, followed by tried and true stepby-step methods pertinent to the subject. Most aspects of current Ad research are covered. The first seven chapters describe how to grow and titer Ads, and how to construct specific alterations in the Ad genome. This is followed by five chapters detailing how to measure apoptosis induced by cells of the immune system, cytokines, and intrinsic apoptosis effectors. Next come in vitro systems to study transcription and splicing. Chapters 18-25 deal with specialized topics.

I thank the contributors for sharing their secrets, John Walker for his patience, and especially Jayma Mikes, without whose expert assistance this work would not have been possible.

William S. M. Wold 


\section{Contents}

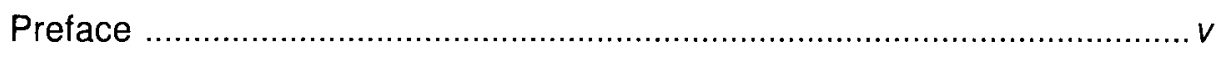

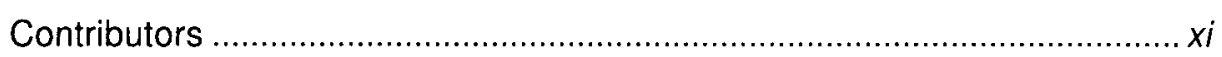

1 Preparation and Titration of $\mathrm{CsCl}$-Banded Adenovirus Stock

Ann E. Tollefson, Terry W. Hermiston, and William S. M. Wold ...... 1

2 Construction of Mutations in the Adenovirus Early Region 3 (E3)

Transcription Units

Terry W. Hermiston, Ann E. Tollefson, and William S. M. Wold .... 11

3 Isolation, Growth, and Purification of Defective Adenovirus Deletion

Mutants

Gary Ketner and Julie Boyer

4 Manipulation of Early Region 4

Julie Boyer and Gary Ketner

5 Adenovirus DNA Packaging: Construction and Analysis of Viral Mutants

Susanne I. Schmid and Patrick Hearing

6 Methods for Creating and Analyzing Adenovirus Vectors that

Express Proteins that Act on the Viral Genome

C. S. H. Young, Andrea L. Nicolás, Heng Lu, and Patricia L. Munz.

7 Construction of Mouse Adenovirus Type 1 Mutants

Angela N. Cauthen and Katherine R. Spindler

8 Generation of Adenovirus-Specific Cytotoxic T Lymphocytes

Tim E. Sparer and Linda R. Gooding 105

9 Measurement of Macrophage-Mediated Cytolysis of Adenovirus-

Infected Cells

Penelope J. Duerksen-Hughes and Linda R. Gooding

10 Measurement of Tumor Necrosis Factor (TNF) Lysis of AdenovirusInfected Cells

Joanna L. Shisler and Linda R. Gooding 121 
11 Role of Natural Killer (NK) Cells in Immunity to Adenoviruses John M. Routes

12 Determination of the Transforming Activities of Adenovirus Oncogenes

T. Subramanian and G. Chinnadurai 143

13 Cell Survival and Apoptosis Assays for E1B 19K and Bcl-2 Family Members

T. Subramanian and G. Chinnadurai 151

14 In Vitro Transcription: Probing the Molecular Functions of Adenovirus Regulatory Proteins

Paul M. Loewenstein, Chao-Zhong Song, and Maurice Green .... 157

15 Cell Microinjection: In Vivo Analysis of the Functional Domains of Viral Regulatory Proteins

Maurice Green, Andrew Thorburn, and Paul M. Loewenstein .... 169

16 Immunoprecipitation of E1A-Containing Protein Complexes Elizabeth Moran and Peter Yaciuk 195

17 Preparation of Splicing-Competent Nuclear Extracts from Adenovirus-Infected Cells Oliver Mühlemann and Göran Akusjärvi 203

18 Adenovirus Entry into Cells: A Quantitative Fluorescence Microscopy Approach

Urs F. Greber, Michel Y. Nakano, and Maarit Suomalainen

19 Simultaneous Detection of RNA and Proteins in

Adenovirus-Infected Cells by Fluorescence

In Situ Hybridization (FISH) and Immunostaining

Eileen Bridge 231

20 Characterization of the Adenovirus Fiber Protein

Jeffrey A. Engler, Barbara Mulach, and Jeong Shin Hong

21 Large-Scale Purification and Crystallization of Adenovirus Hexon John J. Rux, Donatella Pascolini, and Roger M. Burnett 259

22 Adenovirus Protease Joseph M. Weber

23 Methods for Growth and Purification of Enteric Adenovirus Type 40 Vivien Mautner 283

24 Transfection Complexes Generated with Adenovirus and Polyethylenimine-Condensed DNA Matt Cotten, Mediyha Saltik, and Adam Baker 295 
Contents

25 Phylogenetic Analysis of Adenovirus Sequences: Proof of the Necessity of Establishing a Third Genus in the Adenoviridae Family

Balázs Harrach and Mária Benkö

Index 


\section{Contributors}

Göran AKusıärvi - Department of Medical Immunology and Microbiology,

Biomedical Center, Uppsala University, Uppsala, Sweden

AdAM BAKer - Institute for Molecular Pathology, Vienna, Austria

MÁria BeNKö • Veterinary Medical Research Institute, Hungarian Academy of Sciences, Budapest, Hungary

JULIE BOYER - Department of Molecular Microbiology and Immunology,

School of Hygiene and Public Health, Johns Hopkins University,

Baltimore, $M D$

EILeen Bridge - Department of Medical Genetics, Biomedical Center, Uppsala University, Uppsala, Sweden

Roger M. Burnett - The Wistar Institute, Philadelphia, PA

Angela N. Cauthen - Department of Genetics, University of Georgia, Athens, GA

Govindaswamy Chinnadural • Institute for Molecular Virology, St. Louis

University School of Medicine, St. Louis, MO

Matt Cotten - Institute for Molecular Pathology, Vienna, Austria

Penelope J. Duerksen-Hughes - Department of Biology, Georgia State University, Atlanta, GA

JefFrey A. EngLer - Department of Biochemistry and Molecular Genetics, University of Alabama at Birmingham, $A L$

Linda R. Gooding • Department of Microbiology and Immunology, Emory University School of Medicine, Atlanta, GA

URS F. GREBER - Institute of Zoology, Section of Cell Biology, University of Zürich, Zürich, Switzerland

Maurice Green - Institute for Molecular Virology, St. Louis University School of Medicine, St. Louis, MO

BaLȦZS HaRrach • Veterinary Medical Research Institute, Hungarian Academy of Sciences, Budapest, Hungary

Patrick Hearing - Department of Microbiology, Health Sciences Center, State University of New York, Stony Brook, NY

Terry W. Hermiston • Onyx Pharmaceuticals, Richmond, CA 
Jeong Shin Hong - Department of Biochemistry and Molecular Genetics, University of Alabama at Birmingham, $A L$

GARY KETNER - Immunology and Infectious Diseases Department, School of Public Health, Johns Hopkins University, Baltimore, MD

Paul M. Loewenstein • Institute for Molecular Virology, St. Louis

University School of Medicine, St. Louis, MO

Heng Lu • Department of Microbiology, College of Physicians and Surgeons, Columbia University, New York, NY

VIVIEN MAUTNER • CRC Institute for Cancer Studies, The University of Birmingham, Edgbaston, Birmingham, UK

Elizabeth Moran - Fels Institute for Cancer and Molecular Biology, Temple University School of Medicine, Philadelphia, PA

Oliver Mühlemann - Department of Medical Immunology and Microbiology, BMC, Uppsala University, Uppsala, Sweden

Barbara Mulach - Department of Biochemistry and Molecular Genetics, University of Alabama at Birmingham, $A L$

Patricia L. Munz - Department of Microbiology, College of Physicians and Surgeons, Columbia University, New York, NY

Michel Y. Nakano - Institute of Zoology, Section of Cell Biology, University of Zeurich, Zurich, Switzerland

Andrea L. Nicolás - Department of Microbiology, College of Physicians and Surgeons, Columbia University, New York, NY

Donatella Pascolini • Department of Biochemistry/Sciences II, University of Geneva, Switzerland

JoHn M. Routes - Department of Medicine, National Jewish Center for Immunology and Respiratory Medicine, Denver, $\mathrm{CO}$

JoHN J. Rux • Department of Biochemistry/Sciences II, University of Geneva, Switzerland

Mediyna Saltik - Institute for Molecular Pathology, Vienna, Austria

SUSANNE I. SCHMID - Department of Molecular Genetics and Microbiology, Health Sciences Center, State University of New York, Stony Brook, NY Joanna ShISLER - National Institute of Allergy and Infectious Diseases, National Institutes of Health, Bethesda, MD

Снао-Zhong Song - Institute for Molecular Virology, St. Louis University School of Medicine, St. Louis, $M O$

TIM E. SPARER - Department of Microbiology and Immunology, Emory University School of Medicine, Atlanta, GA 
Katherine R. SPINDler - Department of Genetics, University of Georgia, Athens, $G A$

T. Subramanian - Institute for Molecular Virology, St. Louis University School of Medicine, St. Louis, MO

MaArit Suomalainen - Institute of Zoology, Section of Cell Biology, University of Zeurich, Zurich, Switzerland

ANDREW ThORBURn - Institute for Molecular Virology, St. Louis University School of Medicine, St. Louis, MO

Ann E. Tollefson - Department of Molecular Microbiology and Immunology, St. Louis University School of Medicine, St. Louis, MO JOSEPH M. WEBER - Department of Microbiology, University of Sherbrooke, Quebec, Canada

William S. M. Wold - Department of Molecular Microbiology and Immunology, St. Louis University Health Science Center, St. Louis, $M O$

Peter Yaciuk - Department of Molecular Microbiology and Immunology, St. Louis University School of Medicine, St. Louis, MO

C. S. H. Young • Department of Microbiology, College of Physicians and Surgeons, Columbia University, New York, NY 